Brit. J. Ophthal. (1958) 42, 705.

\title{
COMMUNICATIONS
}

\section{EXPERIMENTAL TRACHOMA PRODUCED BY CULTURED VIRUS}

BY

L. H. COLLIER, * STEWART DUKE-ELDER, $\dagger$ AND BARRIE R. JONES $\dagger$

* Medical Research Council, Trachoma Research Group, Lister Institute of Preventive Medicine, and the + Institute of Ophthalmology, University of London.

BECAUSE it has been authoritatively estimated that a quarter of the inhabitants of the globe are affected by trachoma and because this disease undoubtedly results in more visual incapacity than any other, it is difficult to over-stress the importance of the isolation of the causative agent. The aetiological role of the virus can be proved only by its isolation from trachomatous patients, its serial passage in the laboratory, the subsequent demonstration of its ability to reproduce the clinical picture of trachoma with the development of typical cytoplasmic inclusion bodies, and the re-isolation of the virus. Since animal inoculations in this disease give atypical results, it is unfortunately necessary in the present state of our knowledge to use human volunteers for this purpose.

In a previous paper (Collier and Sowa, 1958) the isolation of viruses from cases of trachoma in Gambia was described, using a technique employed by T'ang, Chang, Huang, and Wang (1957), whereby the virus was grown in the yolk-sac of embryonate eggs. In its morphological and serological characteristics the virus closely resembles those of the psittacosislymphogranuloma group (Fig. 1). It is interesting that the virus has been

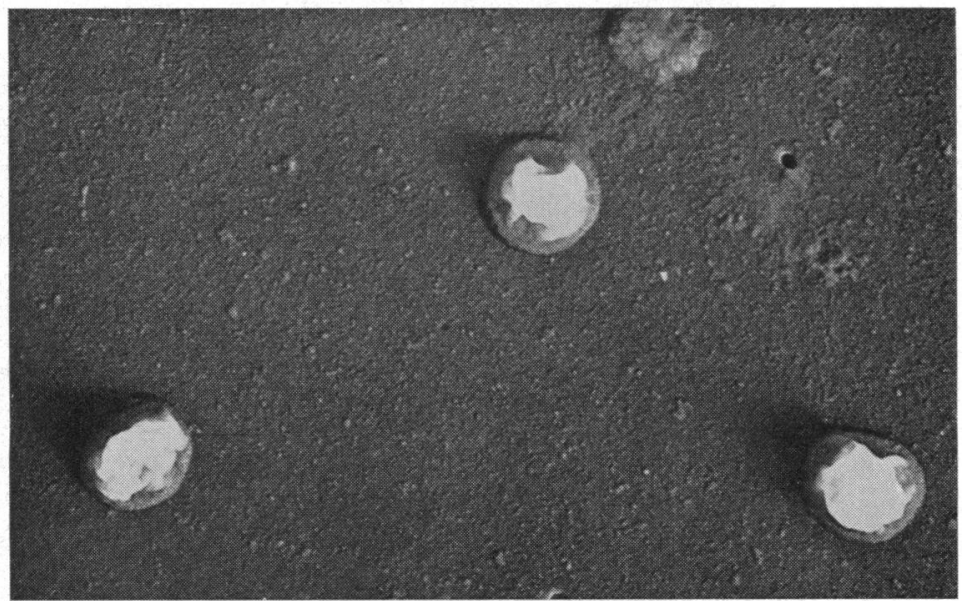

FIG. 1.-Electron-micrograph showing three elementary bodies of the virus of trachoma (strain G1: 8th egg passage). $\times 36,000$. 
recovered from a large proportion of trachomatous subjects in Gambia. In a series of 25 cases diagnosed clinically as trachomatous according to the criteria laid down by the World Health Organization Expert Committee (1956), fourteen were found to have inclusion bodies, and from all fourteen cases virus was recovered. Among the remaining eleven cases which were inclusion-negative, the virus was recovered from five. In fourteen clinically normal controls no virus was recovered.

In the paper noted, the preliminary results were given of an experiment in which a human volunteer was inoculated with one of the viruses isolated in Gambia (called the G1 strain). This volunteer has now been observed, untreated, for 7 months, and the present communication describes in detail the clinical findings and laboratory investigations. An account is also given of a second (and third) human inoculation experiment yielding equivocal results.

\section{MATERIAL AND MethodS}

Virus.-The G1 strain, isolated from a trachomatous patient in the Gambia (Collier and Sowa, 1958), was used for inoculation.

Inoculum.-For both experiments, virus of the 8th egg passage was used. Infected yolk sacs, showing numerous elementary bodies in Giemsa-stained smears, were blended for $1 \mathrm{~min}$. in an M.S.E. homogenizer with four times their weight of 10 per cent. broth-saline. The resulting 20 per cent. (W/W) suspensions were used to inoculate the left eyes of the volunteers. In Experiment I, the yolk sac was stored at $-35^{\circ} \mathrm{C}$. for 3 days before making the suspension, and the latter was kept at $4^{\circ} \mathrm{C}$. for 2 days before use. In Experiment II the yolk sac was stored at $-35^{\circ} \mathrm{C}$. for 9 days before blending, and the final suspension was used on the day of preparation.

Titration of Inocula. - Serial dilutions of infected yolk-sac suspension were made in 10 per cent. broth-saline, and $0.25 \mathrm{ml}$. of each dilution was injected into groups of embryonate eggs by the yolk-sac route. In Experiments I and II, 7-day and 9-day embryos were used respectively for the titrations. This is the only method of assay at present available, and does not always yield consistent results. It is not yet clear whether this is due to variation in the susceptibility of the eggs or to auto-interference due to the presence of relatively large amounts of non-infective virus. For this reason, the infectivity of the inocula used cannot be given in terms of 50 per cent. end-points; the protocols of the titration of inocula used for Experiments I and II are given in full in Table I (opposite). Deaths occurring within 48 hours after inoculation were regarded as non-specific, and are not included in the Table.

Control Yolk-Sac Suspensions. - 20 per cent. suspensions of normal yolk sac, prepared as already described, were used to inoculate the right eyes of both subjects. 
TABLE I

TITRATIONS OF INOCULA USED IN EXPERIMENTS I AND II

\begin{tabular}{c|c|c}
\hline \multirow{2}{*}{$\begin{array}{c}\text { Dilution of } \\
\text { Inoculum }\end{array}$} & \multicolumn{2}{|c}{ Eggs Infected/Eggs Inoculated } \\
\cline { 2 - 3 } & Experiment I & Experiment II \\
\hline $10^{\circ}$ & $2 / 3$ & $1 / 5$ \\
$10^{-1}$ & $3 / 4$ & $0 / 4$ \\
$10^{-2}$ & $2 / 3$ & $0 / 5$ \\
$10^{-3}$ & $2 / 5$ & $0 / 5$ \\
$10^{-4}$ & $4 / 5$ & $0 / 5$ \\
\hline
\end{tabular}

Bacteriological Sterility Tests.-After harvesting, smears of all yolk sacs were stained by Gram's method; no bacteria were found. Digest broth and Brewer's thioglycollate media seeded with portions of yolk sac showed no bacterial growth after incubation at $37^{\circ} \mathrm{C}$. for 5 days. Confirmatory tests, made by seeding the final suspensions onto 5 per cent. horse-blood agar plates, were negative.

Inoculation Technique.-After the conjunctiva had been anaesthetized by the instillation of 4 per cent. cocaine, the left upper lid was everted and the tarsal conjunctiva and upper fornix were rubbed firmly with a small cotton-wool swab moistened with the infected yolk-sac suspension. The right eye was similarly treated with normal yolk-sac suspension.

Examinations for Inclusions. - After the instillation of 4 per cent. cocaine, the lids were everted and scraped with a small metal spatula. The material obtained was spread on a slide, allowed to dry, and stained by two methods.

(i) Iodine Staining was done by the method of Smith, Gilkes, and Sowa (1958). After examination the slides were decolorized by overnight immersion in absolute methyl alcohol and then stained with Giemsa-May-Grünwald as described below.

(ii) Giemsa-May-Grünwald Staining.-After fixation in absolute methyl alcohol, the smears were immersed for $18 \mathrm{hrs}$ in the following solution:

$$
\begin{array}{llll}
\text { Giemsa stain (Gurr's R 66) } & \ldots & \ldots & 1.0 \text { per cent. } \\
\text { May-Grünwald stain (Gurr) } & . . & \ldots & 0.5 \text { per cent. } \\
\text { Distilled water buffered at pH } 6.8 & \ldots & 98.5 \text { per cent. }
\end{array}
$$

After staining, the slides were washed in buffered distilled water and then rapidly in 95 per cent. methyl alcohol, after which they were again transferred to buffered distilled water for several minutes before being dried.

Virus Isolation.-In Experiment I, up to and including 65 days after inoculation, a swab was rubbed over the conjunctiva and placed in $0.5 \mathrm{ml}$. nutrient broth containing $1,000 \mu \mathrm{g}$. streptomycin. After this material had been kept on ice for about $4 \mathrm{hrs}$, the fluid, including that squeezed from the swab, was used to inoculate embryos by the yolk-sac route. Separate groups of three embryos were inoculated with material from the right and left conjunctivae respectively. This procedure was also followed throughout Experiment II. After the 65th day of Experiment I, conjunctival scrapings were added to $0.5 \mathrm{ml}$. 0.85 per cent. saline containing. $10,000 \mu \mathrm{g}$. streptomycin. After storage on ice for $4 \mathrm{hrs}, 0.5 \mathrm{ml}$. 0.85 per cent. 
saline was added, and the material repeatedly drawn up and down in a syringe and needle to break up cell clumps. The suspension was then distributed equally among three eggs as described above.

Complement-Fixation Tests.-These were done by a plate method, based on those of Fulton and Dumbell (1949) and Belyavin (1953). Sera were preserved with sodium azide and stored at $4^{\circ} \mathrm{C}$. They were inactivated at $56^{\circ} \mathrm{C}$. for 30 min. before use. Trachoma virus antigens were prepared from infected yolk sacs. After the virus had been partially purified by differential centrifugation, it was heated at $100^{\circ} \mathrm{C}$. for $20 \mathrm{~min}$. LGV-psittacosis group antigen, similarly prepared from psittacosis virus, was supplied by Professor Barwell. Richardson's preserved complement was difuted to contain 2 MHD per unit volume used in the test.

Haemolytic System.-Sheep cells were thrice washed and diluted to 0.5 per cent. $(\mathrm{V} / \mathrm{V})$ with 0.85 per cent. saline. They were sensitized for $20 \mathrm{~min}$. at room temperature with an equal volume of haemolysin diluted to contain 10 MHD per unit volume.

Diluent.-All reagents, except the sheep cells, were diluted in calcium-magnesium saline.

In the test, the unit volume was $0.05 \mathrm{ml}$., dispensed by dropping pipettes. One vol. each of serum, complement, and antigen were added in this order to the appropriate square on the perspex plates, and the plates were then left overnight at $4^{\circ} \mathrm{C}$, in a moisture-saturated atmosphere. On the following day two vols sensitized cell suspension were added to each square, and the plates were held at $37^{\circ} \mathrm{C}$. in a moist atmosphere for 35 minutes. The degree of lysis in each square was then observed. The serum titre was taken as the highest dilution giving complete $(++++)$ or almost complete $(+++)$ fixation. Appropriate controls for all reagents were included in each test.

\section{EXPERIMENT I}

\section{RESULTS}

The blind volunteer was a white man, aged 71 , whose right and left eyes were enucleated in 1955 and 1957 respectively after loss of sight from lensinduced uveitis with secondary glaucoma, following a blow on the right eye in 1954. His sockets were comfortable and gave rise to only a slight mucoid discharge (Fig. 2, opposite). The shape of the sockets made eversion of the upper tarsal plate difficult, but there was no entropion and, having declined prostheses, he preferred to wear dark glasses. For 4 months before the inoculation there had been no inflammation of either socket and he had used only sodium bicarbonate lotion twice daily. He continued to use this throughout the experiment to remove any discharge.

Clinical Course (Table II).-After inoculation of his left socket on March 11,1958 (D 0), the man was seen next on day seven (D 7) when he complained of soreness of the left socket which had begun on D 2. The right socket appeared unchanged and remained so, except for slight hyperaemia 


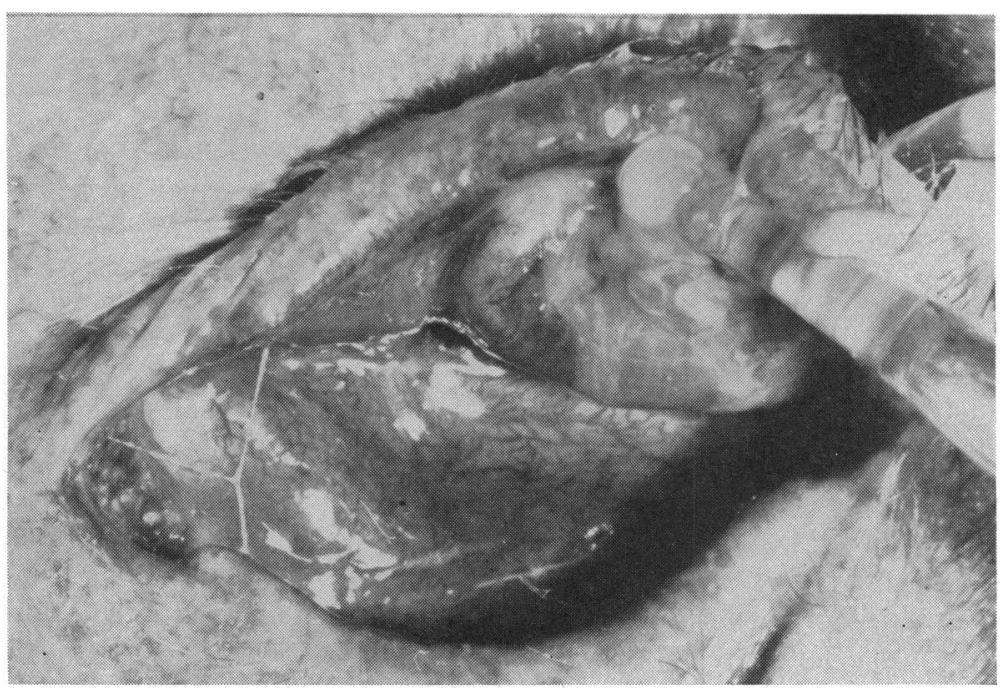

FIG. 2.-Experiment I, left socket before inoculation (D 0).

TABLE II

EXPERIMENT I: SUMMARY OF CLINICAL COURSE

\begin{tabular}{|c|c|c|c|c|c|c|c|c|c|}
\hline $\begin{array}{c}\text { Day } \\
\text { after } \\
\text { Inocula- } \\
\text { tion }\end{array}$ & $\begin{array}{c}\text { Dis- } \\
\text { comfort }\end{array}$ & Discharge & Injection & Oedema & $\begin{array}{c}\text { Diffuse } \\
\text { Infiltra- } \\
\text { tion }\end{array}$ & $\begin{array}{l}\text { Papillary } \\
\text { Hyper- } \\
\text { trophy }\end{array}$ & Follicles & $\underset{\text { trization }}{\text { Cica- }}$ & $\begin{array}{r}\text { Adeno- } \\
\text { pathy }\end{array}$ \\
\hline D 2 & +++ & ++ & & & & & & & \\
\hline D 7 & ++ & $+t+$ & ++++ & $+t+t$ & $++t$ & & & & \\
\hline D 10 & + & +++ & +++ & ++++ & +++ & ++ & & & \\
\hline D 14 & + & +++ & +++ & ++++ & $++t$ & ++ & & & \\
\hline D 17 & + & ++++ & +++ & +++ & +++ & ++ & + & & \\
\hline D 21 & + & $+++t$ & ++++ & +++ & +++ & $++t$ & ++ & & ++ \\
\hline D 28 & & +++ & ++++ & ++ & +++ & +++ & ++ & & + \\
\hline D 35 & & ++++ & $+++t$ & ++ & $++t$ & & ++ & & + \\
\hline D 42 & & +++ & ++++ & & $+++t$ & & +++ & & \\
\hline D 49 & & $++t$ & $+t+$ & & ++++ & +++ & +++ & & \\
\hline \multirow[t]{2}{*}{ D 91} & & ++ & +++ & & +++ & ++++ & ++++ & & \\
\hline & $\begin{array}{c}\text { Biopsy } \\
\text { D } 98++ \\
\end{array}$ & & & & & & & & \\
\hline D 105 & & +++ & +++ & ++ & +++ & ++++ & ++++ & ++ & \\
\hline D 119 & & ++ & +++ & & +++ & ++++ & ++++ & ++ & \\
\hline \multirow[t]{2}{*}{ D 141} & & ++ & ++ & & +++ & +++ & ++++ & ++ & \\
\hline & $\begin{array}{c}\text { Biopsy } \\
\text { D } 141++\end{array}$ & & & & & & & & \\
\hline D161 & & ++ & ++ & & +++ & +++ & $+++t$ & ++ & \\
\hline D188 & & ++ & ++ & & +++ & +++ & ++++ & ++ & \\
\hline
\end{tabular}


and stickiness which developed after a conjunctival scraping on D 14 and resolved by $\mathrm{D} 17$, whereafter it remained normal until mild changes appeared on D 141.

On D 7 the left socket had a fairly profuse mucopurulent discharge and the entire conjunctiva was intensely congested and oedematous (Fig. 3). The "bulbar" conjunctiva and plica showed a gelatinous oedema, and the conjunctiva of the tarsi and fornices was opaque and diffusely infiltrated. The pre-auricular nodes were not palpable. The soreness of the left socket had diminished by D 10 . By D 14 there was intense papillary hyperplasia of the tarsal conjunctiva and a further increase in the diffuse infiltration. The mucopurulent discharge increased and on D 17, amid the general congestion and papillary hypertrophy, pale avascular foci were visible with the slit lamp. These were most marked in the lower lid and in the upper fornix, but were present also, on the upper tarsal plate. By D 21 these foci had enlarged to form follicles giving an appearance of granularity which was visible to the naked eye. The upper tarsal plate showed increasing papillary hypertrophy. The left pre-auricular node was palpable and slightly tender.

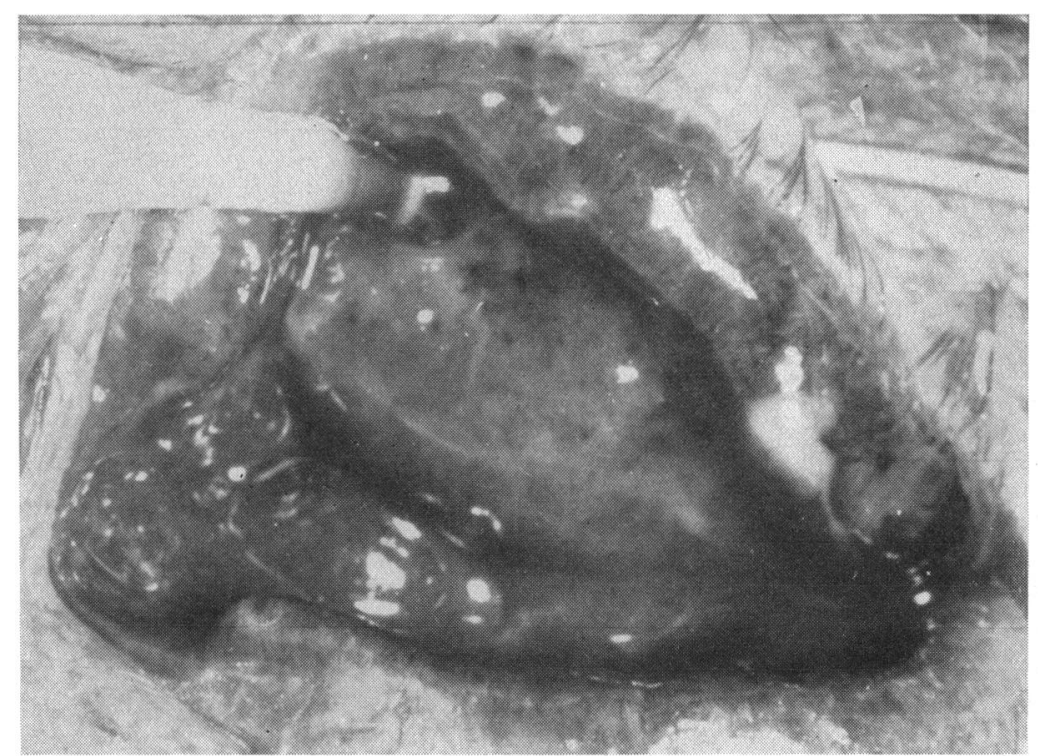

FIG. 3.-Experiment I, D 7, intense oedema and injection of the conjunctiva with mucopurulent discharge.

Examinations on D 28, 35, 42, and 49 showed a continuing mucopurulent discharge. The conjunctival injection became paler as increasing diffuse follicular infiltration obscured the congested blood vessels and the oedema subsided. The tarsal and retrotarsal conjunctiva became more frankly granular (Fig. 4, opposite). Discomfort diminished whilst the pre-auricular node lost its tenderness (D 28) and became impalpable (D 42). 


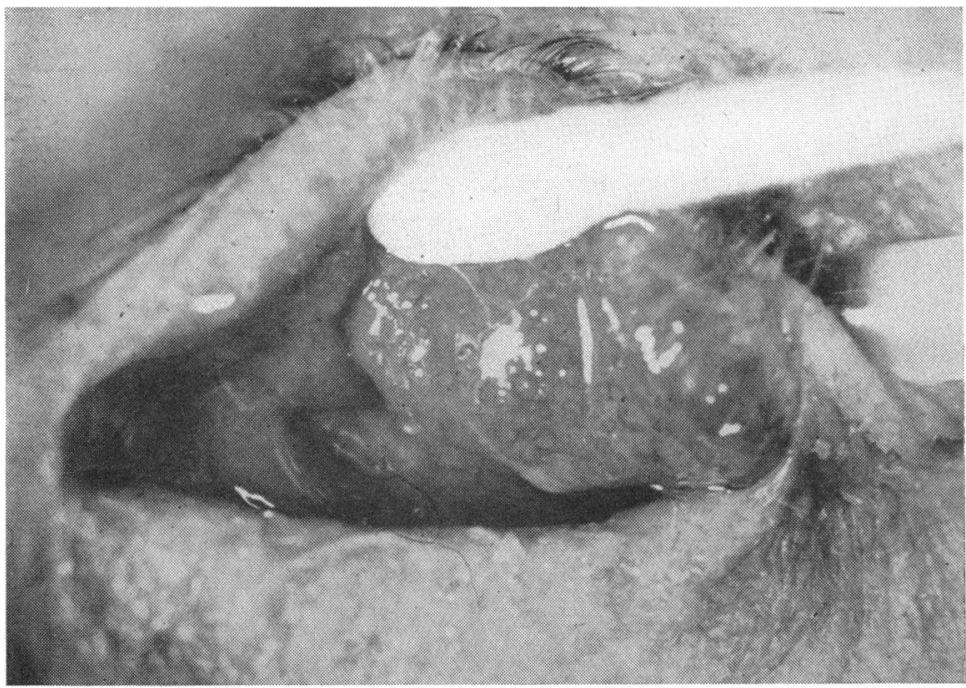

Fig. 4.-Experiment I, D 49, development of follicles on the upper lid.

During the third month (D 91) the conjunctiva slowly became less inflamed and less oedematous. Tarsal papillary hypertrophy persisted, follicles (some with a faintly yellowish tinge) continued to develop, especially in the upper and lower fornices, but also on the plica and on what had formerly been bulbar conjunctiva.

On D 98 under topical anaesthesia withococaine 4 per cent. and adrenalin $1 / 1,000$, a biopsy was taken from the left lower fornix. Streptomycin drops were given for use three times a day for one week. On D 105 the more acute signs of inflammation recurred. Follicles were more marked on the upper lid and some fine linear and stellate scars could be seen with the slit lamp in the lower fornix, lateral to the site of the biopsy.

In the fourth month (D 119) the discharge decreased and the whole condition assumed a less florid and more chronic appearance. The upper tarsal area continued to show chiefly papillary hypertrophy, but the follicles in the upper fornix became very large and extremely friable.

During the fifth month (D 141) the conjunctiva of the right socket became less transparent and showed a slight diffuse infiltration in the lower tarsal and retrotarsal conjunctiva; the small follicles which had been present in the lower fornix enlarged. On D 161 the right socket had not altered materially. On D 188 the conjunctiva of the right lower fornix and lid still showed slight diffuse infiltration with a few small follicles in the fornix. The appearance of the right socket on D 141 suggested that infection had been transferred from the left socket, but the minimal development observed on D 161 and D 188 made this interpretation doubtful.

Under topical anaesthesia further biopsies were taken on D 141 from the left upper and lower fornices and from the upper border of the left upper 
tarsal plate. The follicles ruptured with extreme ease. On D 161 the changes in the left socket continued to assume an even more chronic appearance.

On D 188 the left socket was less inflamed, and the thickening of the conjunctiva and the follicles in the lower lid and fornix were diminishing, whereas the follicles in the upper retrotarsal area were larger, some with a yellowish tinge (Fig. 5). The biopsy sites had healed with small scars and there had been only a slight increase in the number of small linear cicatrices among the follicles.

On D 219 the left conjunctiva showed a reduced amount of injection; the follicles were fewer and less florid and there were more stellate cicatrices.

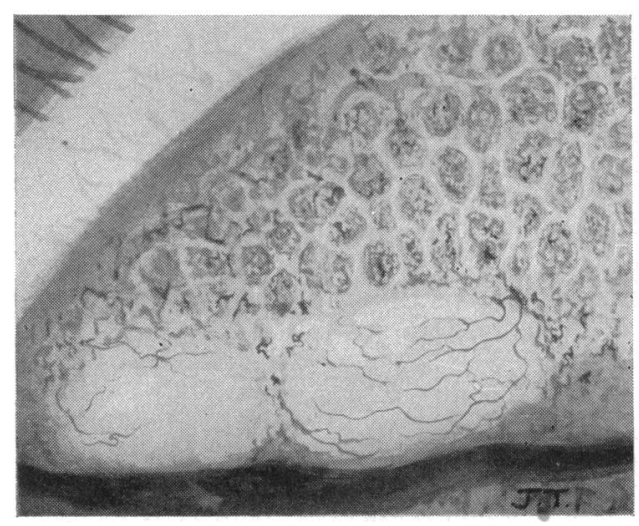

Fig. 5.-Experiment I, D 188, artist's drawing of the inner end of left upper lid, showing tarsal papillary hypertrophy and two very large follicles at the border of the tarsal plate.

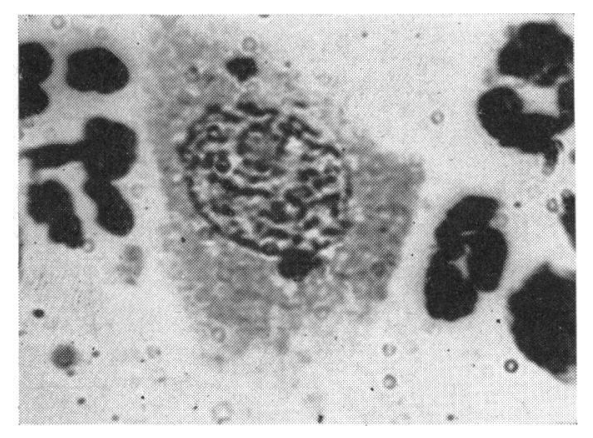

FIG. 6.-Experiment I, D 10, conjunctival scraping from left socket, showing two basophilic initial bodies in the cytoplasm of an epithelial cell. Stained Giemsa-MayGrünwald. $\times 1,010$.

\section{Laboratory Investigations}

Cytology of Conjunctival Scrapings.-During the month following inoculation the epithelial cells of the left socket showed marked degenerative changes, with vacuolation of the nuclei and cytoplasm. After this time they became comparatively normal in appearance although cell debris was always present. The exudate consisted of polymorphs, lymphocytes, plasma cells, and large mononuclear cells; relatively greater numbers of polymorphs were present during the first 3 weeks (Table III, opposite).

Scrapings from the right socket showed normal epithelial cells, with moderate numbers of polymorphs. Occasional lymphocytes were found, and on two occasions (D 133 and D 160) scanty plasma cells were seen. These findings are in accordance with the presence of a low-grade inflammation such as is commonly present in a socket owing to the loss of the normal cleansing circulation of tears.

Inclusions.-On D 7 and 14, numerous particles, staining red with Giemsa, were seen lying free or sometimes within the cytoplasm of epithelial cells. These particles resembled elementary bodies in size and in staining characteristics. They were rarely observed after the 14th day. Initial body forms were found more 
frequently during the early stages, (Fig. 6) and were particularly numerous on D 14 and $\mathrm{D} 17$.

TABLE III

EXPERIMENT I: SUMMARY OF INVESTIGATIONS DONE ON CONJUNCTIVAL SCRAPINGS FROM LEFT CONJUNCTIVA

\begin{tabular}{|c|c|c|c|c|c|c|}
\hline \multirow{2}{*}{$\begin{array}{c}\text { Day } \\
\text { after } \\
\text { Inoculation }\end{array}$} & \multirow[b]{2}{*}{ Inclusions } & \multirow{2}{*}{$\begin{array}{l}\text { Virus } \\
\text { Isolation } \\
\text { in Eggs }\end{array}$} & \multicolumn{4}{|c|}{ Cytology } \\
\hline & & & $\begin{array}{l}\text { Polymorpho- } \\
\text { nuclear } \\
\text { leucocytes }\end{array}$ & Lymphocytes & Plasma cells & $\begin{array}{c}\text { Mononuclear } \\
\text { leucocytes }\end{array}$ \\
\hline D 7 & + & Not attempted & $++t+$ & +++ & ++ & +++ \\
\hline D 10 & ++ & Negative & $+++t$ & ++ & ++ & ++ \\
\hline D 14 & ++ & Positive & $++t$ & +++ & ++ & ++ \\
\hline D 17 & +++ & Eggs contaminated & $+t+t$ & $+t+$ & +++ & $++t$ \\
\hline D 21 & +++ & Eggs contaminated & ++++ & +++ & ++ & ++ \\
\hline D 28 & ++ & Positive & ++ & + & + & + \\
\hline D 35 & +++ & Negative & +++ & +++ & + & ++ \\
\hline D 42 & - & Positive & ++++ & ++ & + & ++ \\
\hline D 49 & + & Negative & +++ & ++ & ++ & ++ \\
\hline D 65 & Not examined & Positive & & Not ex & amined & \\
\hline D 77 & ++ & Positive & ++ & ++ & + & + \\
\hline D 91 & + & Positive & ++ & +++ & + & + \\
\hline D 105 & ++ & Positive & ++++ & ++ & + & + \\
\hline D 119 & + & Eggs contaminated & ++ & +++ & + & ++ \\
\hline D 133 & + & Eggs contaminated & ++++ & ++ & ++ & +++ \\
\hline D 141 & + & Positive & ++++ & +++ & ++ & ++ \\
\hline D 161 & ++ & Eggs contaminated & ++ & +++ & ++ & ++ \\
\hline
\end{tabular}

Scanty but typical Halberstaedter-Prowazek bodies were observed on D 7, and then became more numerous (Fig. 7, overleaf). From D 17 to D 35 there were often several visible in single-high-power fields, and they were found at every subsequent examination except one, although tending to diminish in number during the latter part of the experiment (Table III).

The inclusion bodies were typical of those seen in natural trachoma, and the presence of a carbohydrate matrix was repeatedly demonstrated by iodine staining (Fig. 8, overleaf).

Inclusions were never found in scrapings from the right socket.

Histology.--On two occasions, conjunctival biopsies were taken. Sections were stained with haematoxylin and eosin, Giemsa, and Masson's stain. In thin Giemsa stained sections, cytoplasmic inclusions were readily demonstrated in the epithelial cells of both these specimens. The histological findings were as follows:

Conjunctival biopsy (D 98.)._-"Many of the conjunctival epithelial cells show degenerative changes in the nucleus and cytoplasm. Occasionally, polymorphonuclear 


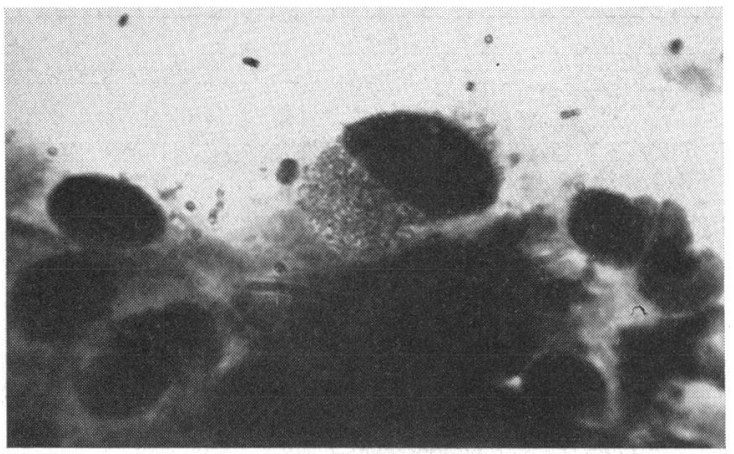

Fig. 7.-Same field as Fig. 8 after decolorization and restaining with Giemsa-MayGrünwald.

FiG. 8.-Experiment I, D 105, Halberstaedter-Prowazek body in conjunctival scraping. Stained with iodine to show carbohydrate matrix. $\times 800$.

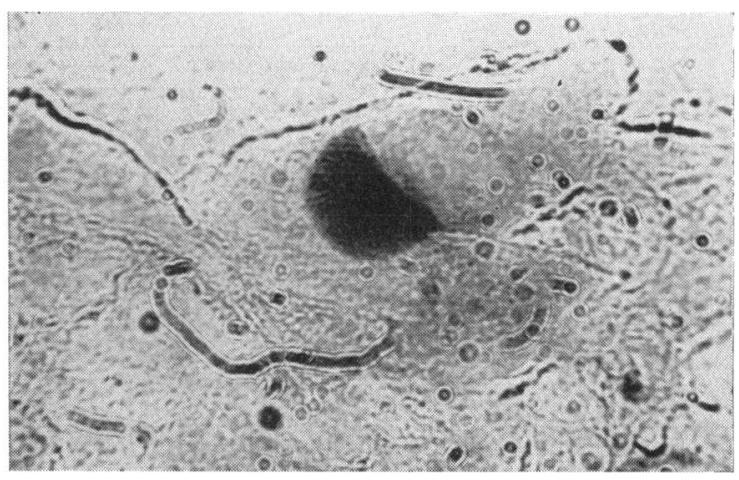

leucocytes and plasma cells have penetrated the epithelial layer. Immediately under the epithelium there is an area of dense infiltration consisting mostly of plasma cells, but showing also polymorphonuclear cells, lymphocytes, and macrophages. Below this area is a well-defined follicle with a central mass of pale-staining cells showing many mitoses, and a peripheral zone of lymphocytes and plasma cells in which the lymphocytes predominate."

Conjunctival Biopsy (D 140) (Prof. N. Ashton, Institute of Ophthalmology)."Sections show two small fragments of tissue in which the histological changes are essentially the same. Immediately beneath the atrophic conjunctival epithelium there is a dense chronic inflammatory infiltration in which plasma cells predominate and in which much nuclear debris is present. In the larger segment there is a well-defined follicle consisting centrally of large pale mononuclear cells in active mitosis, and peripherally of lymphocytes and plasma cells (Figs 9 and 10, opposite). There is a mild degree of fibrosis in the adjacent stroma but not within the infiltrations."

Serology.-Complement-fixation tests were made on sera taken just before inoculation, and on D 14, 21, and 42. The results were surprising (Table IV, opposite). Before inoculation, the serum titre against the Chinese strain of trachoma virus was $1 / 32$, and a titre of $1 / 64$ was obtained with the G1 strain used for inoculation and with the psittacosis-lymphogranuloma group antigen; 2 weeks after inoculation the same values were obtained, but at 3 and 6 weeks after inoculation the titres had increased to $1 / 128$ with all three antigens. 


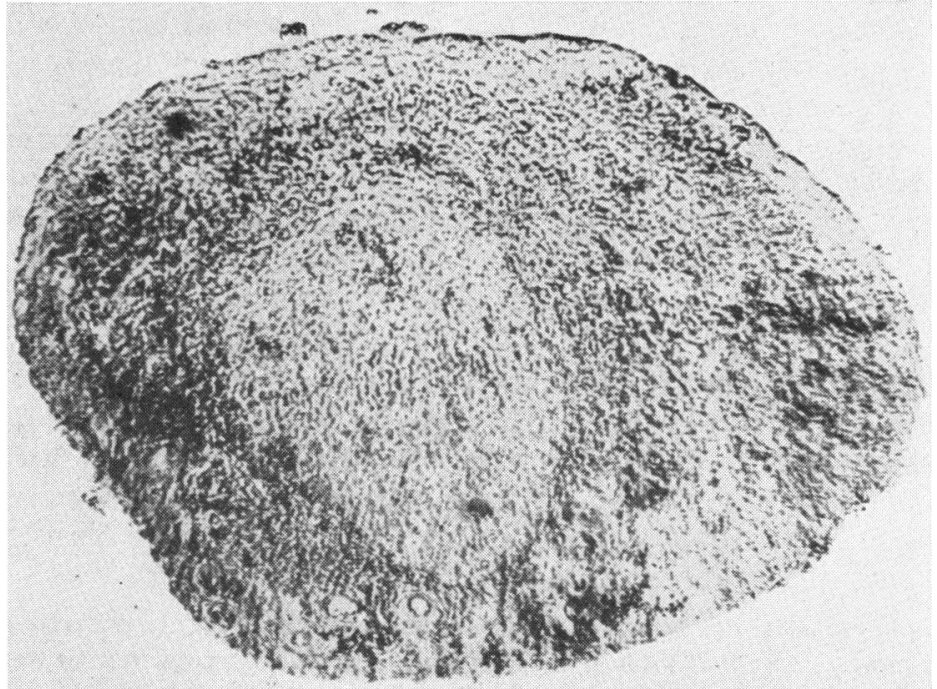

Fig. 9.-Experiment I, D 98, conjunctival biopsy, showing low-power view of follicle with well defined central area of pale-staining cells and denser peripheral zone of lymphocytes and plasma cells. Stained haematoxylin and eosin. $\times 75$.

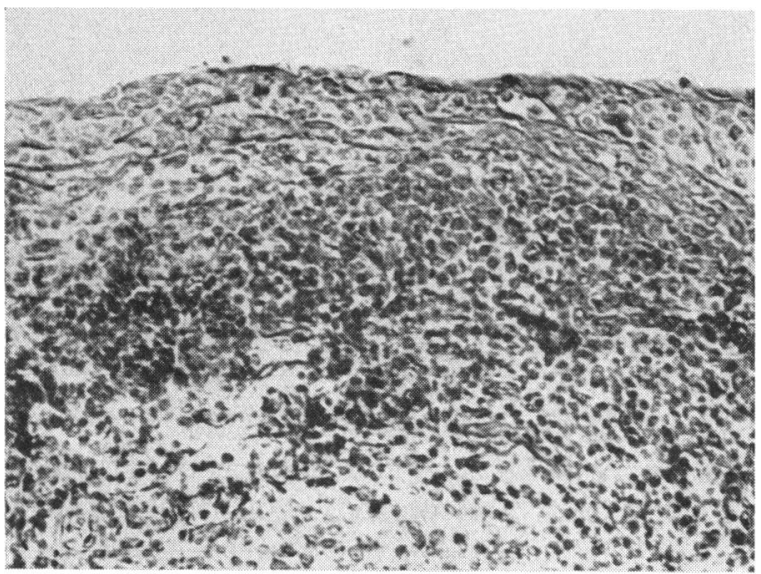

FIG. 10.-Experiment I. D 98, conjunctival biopsy, showing intense subepithelial infiltration by plasma cells, lymphocytes, and macrophages. Stained haematoxylin and eosin. $\quad \times 180$.

TABLE IV

EXPERIMENT I : COMPLEMENT-FIXATION TESTS ON SERA OF:HUMAN SUBJECT

\begin{tabular}{|c|c|c|c|c|c|c|c|}
\hline & & & & \multicolumn{4}{|c|}{ Serum Titre } \\
\hline \multirow{2}{*}{\multicolumn{4}{|c|}{ Antigen }} & \multirow{2}{*}{$\begin{array}{c}\text { Before } \\
\text { Inoculation }\end{array}$} & \multicolumn{3}{|c|}{ After Inoculation } \\
\hline & & & & & D 14 & D 21 & D 42 \\
\hline \multirow[t]{2}{*}{ Trachoma Virus } & Strain G & . & . & $1 / 64$ & $1 / 64$ & $1 / 128$ & $1 / 128$ \\
\hline & T'ang's $S$ & rain TE 55 & . & $1 / 32$ & $1 / 32$ & $1 / 128$ & $1 / 128$ \\
\hline \multicolumn{2}{|c|}{ Psittacosis Antigen } & .. & $\cdots$ & $1 / 64$ & $1 / 64$ & $1 / 128$ & $1 / 128$ \\
\hline \multicolumn{2}{|c|}{ Normal Yolk-sac Control } & . & $\ldots$ & $<1 / 4$ & $<1 / 4$ & $1 / 4$ & $<1 / 4$ \\
\hline
\end{tabular}


In view of these results, the possibility of a past infection with another virus of the psittacosis-lymphogranuloma group was considered, although there was no history suggestive of such an episode. On D 119 the subject was Frei-tested; 48 hrs later there was no reaction to the control antigen, but an erythematous papule $10 \times 11$ $\mathrm{mm}$. had developed at the site of injection of the test antigen. This result strongly suggests past infection with a lymphogranuloma virus. It is most unlikely to have been due to the experimental trachoma infection, since we have found in Gambia that children suffering from natural trachoma are consistently Freinegative.

Virus Isolation.-During the course of the experiment, repeated attempts were made to isolate virus from both right and left sockets by yolk-sac inoculation. The results are given in Table III. Virus was first obtained from the left socket 2 weeks after the start of the experiment and was isolated on seven subsequent occasions. It was still present 20 weeks after inoculation. Virus was never recovered from the right socket.

Bacteriology.-At intervals, cultures were made from both sockets on aerobic blood agar plates. On D 7, 17, and 21, growths of Corynebacterium xerosis were obtained from both sockets. On D 17, two colonies of micrococci were grown from the left socket.

Haematology.-The results of blood counts and erythrocyte sedimentation rate determinations have been previously reported (Collier and Sowa, 1958). No gross variations from normal values were observed.

\section{EXPERIMENT II}

The second volunteer was a man aged 42 years, who was blind from bilateral congenital optic atrophy. He had no external ocular disease but any examination induced extreme reflex blepharospasm and upward deviation of the globes.

Clinical Course (Table V, opposite).-On March 14, 1958 (D 0), the left eye was inoculated.

The patient was next seen on D 7, when he reported slight irritation in both eyes. Examinations of both eyes on D 7, 11, and 14, showed no pathological changes apart from slight conjunctival hyperaemia in the lateral third of each lid of the left eye. The right eye remained unchanged throughout the experiment.

On D 25 the left eye was uncomfortable and watery, and the palpebral conjunctiva injected and thickened. Several small follicles had developed at the outer end of both lids, especially the lower. The left pre-auricular node was palpable and slightly tender.

On D 39 the palpebral conjunctiva was more congested, the lower tarsal conjunctiva was finely granular to the naked eye, and one of the follicles at the outer angle had become moderately large. There was a diffuse roughening of the epithelium on the upper third of the cornea and three small epithelial filaments were present. The eye continued to be slightly watery. On D 46 the conjunctiva was unchanged. Two of the corneal filaments 
TABLE V

EXPERIMENT II: SUMMARY OF CLINICAL COURSE

\begin{tabular}{|c|c|c|c|c|c|c|c|c|}
\hline $\begin{array}{l}\text { Day after } \\
\text { Inoculation }\end{array}$ & Discomfort & $\begin{array}{c}\text { Watery } \\
\text { Discharge }\end{array}$ & Injection & $\begin{array}{c}\text { Diffuse } \\
\text { Infiltration }\end{array}$ & Follicles & $\begin{array}{c}\text { Adeno- } \\
\text { pathy }\end{array}$ & $\begin{array}{l}\text { Roughen- } \\
\text { ing of } \\
\text { Corneal } \\
\text { Epithelium }\end{array}$ & $\begin{array}{l}\text { Punctate } \\
\text { Keratitis }\end{array}$ \\
\hline D 7 & + & & & & & & & \\
\hline D 11 & & & + & & & & & \\
\hline D 14 & & & + & & & & & \\
\hline D 25 & + & + & + & + & + & + & & \\
\hline D 39 & & + & ++ & + & ++ & & + & + \\
\hline D 62 & & + & + & + & + & & & + \\
\hline D 69 & & & & & & & & \\
\hline
\end{tabular}

had desquamated. A punctate epithelial keratitis had developed in the area which had previously shown a diffuse roughening. These lesions were of two types. The first consisted of small groups of fine opaque white dots in the epithelium which stained with bengal rose but not with fluorescein. The second consisted of minute depressions in the epithelium, which stained with fluorescein but not with bengal rose (Fig. 11).

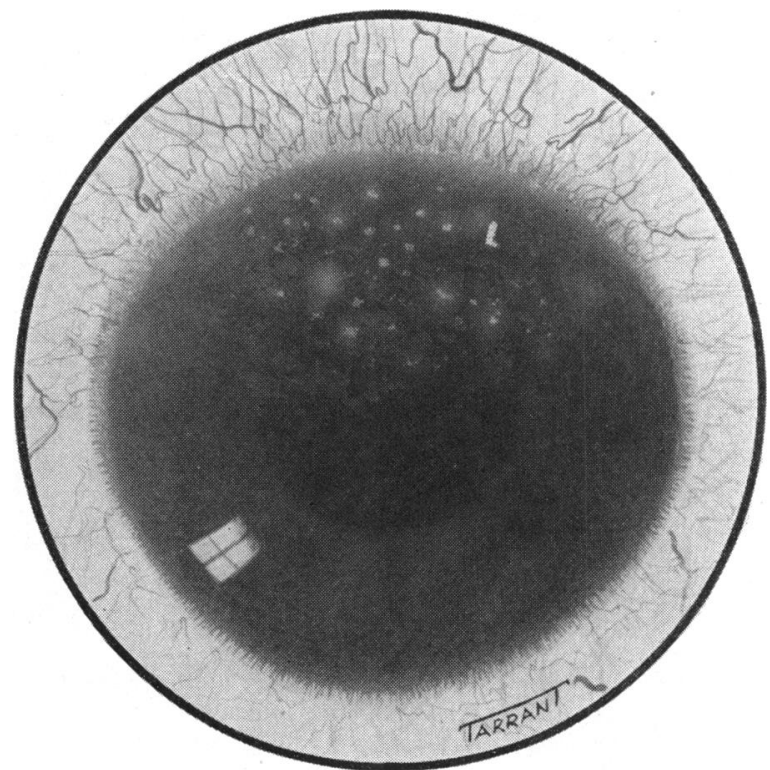

FIG. 11.--Experiment II, D 46, artist's drawing of left cornea, showing punctate epithelial and subepithelial keratitis, one epithelial filament, and congestion of the limbus.

Under some of these lesions there was a faint haze in the superficial stroma. The limbal vessels were congested but no pannus had developed. At this 
stage the clinical appearance of the cornea resembled that of a punctate keratitis of viral origin.

On D 62 the congestion and infiltration of the palpebral conjunctiva had lessened and the follicles had begun to regress. The corneal surface was less rough and the punctate lesions were resolving. The limbus was less congested but one minute cellular subconjunctival infiltration, about $1 \mathrm{~mm}$. in diameter, was present at the limbus at 1 o'clock.

By D 69 the left eye and conjunctiva were again normal.

\section{Laboratory Investigations}

Conjunctival Scrapings.-These were made at intervals up to and including D 46. Scrapings from the left (inoculated) eye showed epithelial cells and a few polymorphs. On D 11 and D 32 moderate numbers of lymphocytes were seen but plasma cells and large mononuclear cells were absent; on no occasion was the cytology typical of trachoma or inclusions found. Scrapings from the right eye showed epithelial cells and occasional polymorphs.

Virus Isolation.-Attempts to isolate virus from the left eye were made on D 25, 32, 39, 47 with negative results.

Bacteriology.-Cultures made from both eyes on D 11 yielded scanty growths of coagulase-negative Staph. albus; a few colonies of Corynebacterium xerosis were grown from the left eye.

Serology.-Before inoculation serum antibody titres of $1 / 4$ were obtained by complement-fixation test against the Chinese strain of trachoma virus and the psittacosis-lymphogranuloma group antigen. The serum titre with the G1 strain was less than 1/4. Serum collected on D 39 showed no increase in these values.

\section{Discussion}

Although pannus has not been induced by experimental inoculation, the results of Experiment I proved good evidence that the virus we have designated as G1 is aetiologically related to trachoma. The mucopurulent papillary and follicular conjunctivitis of acute onset with mild pre-auricular adenitis running a chronic course to produce early cicatrization, the histological appearances, and the cytology of the conjunctival scrapings, were all typical of the findings in natural trachoma and in experimental trachoma transmitted directly from trachomatous eyes (see Tsutsui, 1958, and others). The inclusion bodies in which a carbohydrate matrix was repeatedly demonstrated are found only in trachoma and in inclusion blennorrhoea. Since the virus used to inoculate the volunteers was originally isolated from a case of trachoma with well-marked corneal. infiltration, pannus, and cicatricial changes, the possibility that the G1 strain is a virus responsible for inclusion blennorrhoea can be eliminated. The absence of bacterial conjunctival pathogens and the repeated re-isolation of the virus from the experimental infection amply confirm the presence of the agent at the site of the disease. 
The clinical course in Experiment II is difficult to interpret. The mild acute follicular conjunctivitis with pre-auricular adenitis associated with a diffuse roughening of the upper corneal epithelium, leading to a punctate epithelial and subepithelial keratitis, is suggestive of a mild trachomatous infection. The development of corneal filaments, the rapid resolution, the absence of mucopus, and especially the atypical cytology make this interpretation uncertain. The negative virological investigations do not suggest trachomatous infection. These equivocal results may possibly be explained by the comparatively low infectivity of the inoculum, as measured by egg titration. Since the virus is rather labile, it was not desirable to store the inoculum until the results of the infectivity titration were known. The material used was held for a longer period at $-35^{\circ} \mathrm{C}$. than in Experiment I; although stained smears showed numerous elementary bodies, a significant amount of inactivation may have occurred during storage. On the other hand, the poor titration result may in part be explained by the use of rather older chick embryos than is customary for this work.

The serological findings in Experiment I deserve comment. Whatever the cause might have been for the abnormal level of complement-fixing antibody existing before inoculation, it is apparent that the subject was not protected against the experimental infection. The presence of neutralizing antibody could not be determined, since no test for this is at present available owing to the erratic behaviour of the virus in eggs. The small rise in complementfixing antibody during the course of the experimental infection accords with what is known to occur in the natural disease.

\section{ADDENDUM}

The report of a third case may-or may not-be of interest.

A woman, aged 56, who had previously had both eyes removed for the painful sequelae of iridocyclitis, was admitted to St. George's Hospital, London; clinically both sockets were normal; bacteriologically they showed a scanty growth of coagulase-negative Staph. albus and some diphtheroids. As with the two cases previously reported, the left tarsal conjunctiva was inoculated with yolk-sac suspension infected with the G1 trachoma virus previously used, and the right with normal yolk-sac suspension. Two days later both tarsal conjunctivae showed a marked papillary hypertrophy with some discharge, the changes being more marked on the right side than the left. Three days later, three small follicles appeared on the conjunctiva near the proximal margin of the left upper tarsal plate near the lateral canthus. Meantime, the injection of the right tarsal plate was subsiding and no follicles were present. The next day (6 days after inoculation), after the removal of a tooth, the patient was (inadvertently) given 800,000 units penicillin intramuscularly, and 2 days later the follicles had disappeared; the conjunctivae remained normal in clinical appearance during the following 3 weeks. Conjunctival scrapings were examined 2, 5, and 9 days after inoculation. Material from both inoculated and control sockets showed normal epithelial cells, with moderate numbers of polymorph leucocytes and scanty lymphocytes. The cytology was not 
typical of trachoma and inclusions were not found. Attempts to isolate the virus from the conjunctival sac on the 14th and 21st days proved negative.

There is little doubt that from the clinical point of view the follicles resembled those of trachoma, although the presence of this disease was not confirmed cytologically or virologically. If this infection had begun to establish itself, the rapid disappearance of clinical signs after the systemic administration of penicillin may be of interest in view of the findings recorded in the subsequent paper (Smith, 1958). The evidence, however, is inferential and inconclusive and is merely reported at this stage in the investigation because it may eventually prove to be of confirmatory value to further observations.

\section{SUMMARY}

A case is described of the experimental inoculation of a human volunteer with a virus isolated from a trachomatous patient and subjected to serial passage in the laboratory. The typical clinical and histological picture of trachoma resulted, with the development of inclusion bodies, and the virus was again recovered from the conjunctiva. The evidence that this virus is the causative agent in trachoma is therefore strong.

In view of their possible interest in further investigations, two other inoculation experiments of a less conclusive nature are also described.

The expenses of this research were met in part by grants from the Colonial Development and Welfare Fund. The electron-micrograph was made by Dr. R. Valentine of the National Institute of Medical Research.

Our greatest debt, of course, is to those who volunteered as subjects for inoculation; the observations took much of their time and were potentially capable of causing anxiety and inconvenience to themselves and their families. The first volunteer was a particularly delightful old patient of Moorfields Hospital; the second is an international correspondent at the Royal National Institute for the Blind, London; the third, who had courageously fought a losing battle for her sight for 20 years, was equally willing to put herself at our disposal in the interests of science.

\section{REFERENCES}

Belyavin, G. (1953). J. Hyg., 51, 492.

Collier, L. H., and SowA, J. (1958). Lancet, 1, 993.

Fulton, E., and DumbelL, K. R. (1949). J. gen. Microbiol., 3, 97.

SMITH, C. H. (1958). Brit. J. Ophthal., 42, 721.

, GILKES, M. J., and SoWA, J. (1958). Ibid., 42, 461.

T'ANG, F.-F., Chang, H.-L., HuANG, Y.-T. and WANG, K. C. (1957). Chin. med. J., 75, 429.

TsuTsui, J. (1958). Amer. J. Ophthal., 45, 44. 